\title{
Predicting the return of spontaneous circulation after out-of-hospital cardiac arrest through blood gas analysis
}

\author{
N Umei*, I Shingo, Y Ujike, T Yumoto, A Ida, T Hirayama, N Shiba, K Tsukahara, Y Kinami, M Terado, H Yamanouchi, \\ K Sato, T Ugawa
}

From ESICM LIVES 2015

Berlin, Germany. 3-7 October 2015

\section{Intr}

Several studies have investigated the factors associated with the return of spontaneous circulation (ROSC) in outof-hospital cardiac arrest (OHCA) cases. The most analyzed factor is pre-hospital resuscitation, such as an early phone call for the ambulance, bystander cardiopulmonary resuscitation $(\mathrm{CPR})$, presentation with ventricular fibrillation, and medication. The blood gas parameters have not yet been reported as a predictive factor for ROSC.

\section{Objectives}

This study aimed to determine whether the blood $\mathrm{pH}$, partial carbon dioxide pressure (PC02), bicarbonate $\left(\mathrm{HCO3}^{-}\right)$, hemoglobin, natrium, potassium, lactate, and glucose concentration on admission were able to predict ROSC in patients with OHCA.

\section{Methods}

We performed a retrospective observational study of 186 OHCA patients who visited the emergency department of our hospital from January 2008 to December 2013. Bystander CPR status, initial cardiac rhythm, cause of arrest, the time from call receipt to hospital arrival, sex, age, and parameters of blood gas ( $\mathrm{pH}, \mathrm{PCO}^{2}, \mathrm{HCO3}^{-}$, hemoglobin, natrium, potassium, lactate, and glucose) were measured and compared between the ROSC-achieving patients (ROSC group) and those who did not achieve ROSC (non-ROSC group).

\section{Results}

Among the OHCA patients, 67\% did not achieve ROSC. The patients who did not achieve ROSC had a lower percentage of bystander CPR than those who achieved ROSC (13\% vs. $31 \%$ p = 0.004). The PC02 and potassium levels on admission were significantly higher in the non-ROSC group (84 $\mathrm{mmHg}$ vs. $69 \mathrm{mmHg} \mathrm{P}=0.03$; $6.7 \mathrm{mmol} / \mathrm{l}$ vs. $5.2 \mathrm{mmol} / \mathrm{l} \mathrm{P}<0.01$, respectively). The glucose concentrations were significantly lower in the nonROSC group $(149 \mathrm{mg} / \mathrm{dl}$ vs. $258 \mathrm{mg} / \mathrm{dl} \mathrm{p}<0.01)$. There were no statistically significant differences between both groups for other blood gas parameters. On multivariate analysis, bystander CPR as well as PC02, potassium, and glucose levels were independently associated with ROSC.

\section{Conclusions}

A high blood PC02 level, a high potassium level, and low glucose level measured in OHCA patients on arrival at the hospital is predictive of a poor outcome for ROSC.

Published: 1 October 2015

\section{Reference \\ 1. Yu-Jang Su, Yen-Chun Lai: Optimal parameters for return of spontaneous circulation in resuscitating out-of-hospital cardiac arrest patients. International Journal of Gerontology 2009, 3:96-100.}

\section{doi:10.1186/2197-425X-3-S1-A206}

Cite this article as: Umei et al:: Predicting the return of spontaneous circulation after out-of-hospital cardiac arrest through blood gas analysis. Intensive Care Medicine Experimental 2015 3(Suppl 1):A206. 